between the two modalities. Safety was assessed through quantifying the number of complications with central venous lines $(\mathrm{CVL})$ or external ventricular drains (EVD) attributable to the LUCID device.

Results Nine patients (average age $=66 \mathrm{yrs}$ ) with subarachnoid hemorrhages or aneurysms underwent a total of 21 LUCID TCDs to assess the MCAs for vasospasm. The autonomous motion of the LUCID TCD ultrasound transducers did not displace or impinge on CVLs/EVDs. Moreover, LUCID acquired maximum MCA velocities and angiography moderately agree with a Cohen's Kappa value of 0.61 $(\mathrm{p}=0.005)$.

Conclusions This investigation demonstrates that LUCID TCD as a modality to probe for MCA vasospasm is a viable option as LUCID maximum MCA velocities and angiography are moderately congruent. Additionally, LUCID TCD is safe to use clinically as it poses minimal risk to a patient's CVL or EVD.

Disclosures K. Clare: None. A. Stein: None. J. Cooper: None. C. Gandhi: None. C. Bowers: None. C. Cole: None. J. Santarelli: None. J. Pisapia: None. F. Al-Mufti: None.

\section{E-038 TRANSRADIAL NEURO-ANGIOGRAPHY BY RE-WIRING OF ARTERIAL LINE}

${ }^{1} \mathrm{R}$ Dossani, ${ }^{1} \mathrm{M}$ Waqas*, ${ }^{1} \mathrm{M}$ Tso, ${ }^{1} \mathrm{G}$ Rajah, ${ }^{2} \mathrm{H}$ Rai, ${ }^{1} \mathrm{~A}$ Lewy, ${ }^{1} \mathrm{~A}$ Siddiqui, ${ }^{1} \mathrm{~J}$ Davies. ${ }^{1} \mathrm{U} B$ Neurosurgery, Buffalo, NY; ${ }^{2}$ UB Neurosurgery, BUFFALO, NY

\subsection{6/neurintsurg-2020-SNIS.74}

Background The advantages of transradial neuroangiography over a transfemoral access with respect to fewer access site complications, shorter procedure duration and better patient comfort are well described. Radial arterial lines are routinely placed in the ICU in critically ill neurosurgical patients and in the OR on patients undergoing complex neurovascular procedures. We describe the utility of rewiring a radial arterial line in exchange for an arterial sheath for the purpose of diagnostic cerebral arteriography or neurointervention. Rewiring a radial arterial line has the practical benefit of avoiding repeat needle puncture in the setting of an existing catheter that can be ready exchanged for an arterial sheath using a wire exchange technique.

Methods Consecutive patients who had transradial neuroangiography through arterial line access over the 12 months were included in the study. The technique for transradial access was modified in the presence of arterial line. The Arterial line catheter was re-wired and exchanged with $5 \mathrm{Fr}$ or 6 Fr sheath as necessary. Data on demographics, indication, devices, and complications was recorded and analyzed.

Results Twelve procedures were performed on 11 patients. Mean age was $58.6+12.9$ years; 7 were female. Seven procedures were performed using left-sided arterial line access while 5 procedures were performed using the right side. The most common indication was post-operative angiogram after clipping of aneurysms $(n=8)$, coiling of anterior communicating artery aneurysm $(n=1)$, arteriovenous fistula surgery $(n=1)$. Two cases were performed to evaluate intraventricular hemorrhage $(n=1)$, and arteriovenous malformation resection $(n=1)$. No access site complication was observed. The radial artery sheath was either removed or sutured in place to be used as an arterial line if the patient needed to return to the operating room or the ICU.
Conclusion Arterial line rewiring allows rapid transradial access with an arterial sheath and avoids repeat needle puncture. This improvised approach to transradial interventions is especially useful for immediate post-operative evaluation of vascular disorders.

Disclosures R. Dossani: None. M. Waqas: None. M. Tso: None. G. Rajah: None. H. Rai: None. A. Levy: None. A. Siddiqui: None. J. Davies: None.

\section{E-039 CLINICAL CHARACTERISTICS OF TRAUMATIC BRAIN INJURY PATIENTS UNDERGOING ENDOVASCULAR RESCUE FOR POST-TRAUMATIC VASOSPASM}

${ }^{1} \mathrm{~K}$ Khatibi*, ${ }^{1} \mathrm{~L}$ Ponce Mejia, ${ }^{2} \mathrm{H}$ Saber, ${ }^{1} \mathrm{~N}$ Kenoko, ${ }^{1} \mathrm{R}$ Jahan, ${ }^{1} \mathrm{~S}$ Tateshima, ${ }^{1} \mathrm{M}$ Nour, ${ }^{3} \mathrm{G}$ Colby, ${ }^{1} \mathrm{G}$ Duckwiler, ${ }^{1} \mathrm{~V}$ Szeder. ${ }^{1}$ Radiology, Interventional Neuroradiology, UCLA, Los Angeles, CA; ${ }^{2}$ Neurology, UCLA, Los Angeles, CA; ${ }^{3}$ Neurosurgery, UCLA, Los Angeles, CA

\subsection{6/neurintsurg-2020-SNIS.75}

Background Cerebral vasospasm is a serious sequela of traumatic brain injury (TBI) which leads to further neurologic injury subsequent to the initial trauma. The natural history, associated risk factors, and the optimal treatment strategy is not well understood. We aim to evaluate the clinical and radiographic characteristics of patients with TBI who underwent endovascular rescue therapy for post-traumatic vasospasm (PTV).

Methods This is a descriptive case series of all patients with TBI who underwent endovascular rescue therapy for PTV between October 2017 to November 2019. We studied the clinical characteristics - age, sex, Glascow coma scale (GCS), need for craniotomy or craniectomy, radiographic characteristics on the CT scan on the day of presentation, presence of subarachnoid hemorrhage (SAH), location of SAH, presence of contusion, presence of $\mathrm{SDH}$, and presence of pseudoaneurysm of the patients who underwent rescue therapy. The timing of occurrence of vasospasm, severity of spasm on angiography, type of rescue therapy and dose of medication used were also studied. We evaluated association of these clinical characteristics with cumulative severity of vasospasm observed on angiography. Descriptive statistics were used for analysis.

Results We identified 22 patients with PTV with 69 rescue angiograms performed (mean: 3.2; range: 1-9 angiograms per patient) during this period. Average age upon presentation was 40 -years old, $81 \%$ of the patients were male sex and average GCS was 6.8. Sixty-seven percent of the patients underwent craniotomy or craniectomy. All patients had SAH, though only $60 \%$ had cisternal SAH. Parenchymal contusion was noted on $90 \%$ as well as SDH in $90 \%$. The PTV were noted between 3 to 19 days after trauma. All patients undergoing rescue therapy received verapamil infusion $(5-35 \mathrm{mg})$. There was no correlation $\left(\mathrm{r}^{2}>0.5\right)$ between any of the clinical or radiographic variables studied and cumulative or average severity noted on the angiograms for each patient.

Conclusion Post-traumatic vasospasm can be detected as early as post trauma day 3 to 19 in patients with TBI and SAH. Absence of cisternal SAH does not rule out occurrence of the vasospasm during the course of treatment.

Disclosures K. Khatibi: None. L. Ponce Mejia: None. H. Saber: None. N. Kenoko: None. R. Jahan: None. S. Tateshima: None. M. Nour: None. G. Colby: None. G. Duckwiler: None. V. Szeder: None. 